\title{
Study on Distribution Law of Multicomponent Gases in Coal Mine Gob in a Numerical Simulation Way
}

\author{
Wang Shuguang ${ }^{a}$, Zhu Jincai ${ }^{b}$ Chen Qing $^{c}$, Song Bihong ${ }^{\mathrm{d}}$ \\ Northwest Institute of Nuclear Technology, Shaanxi, Xi'an, 710024, China \\ ahitwsg@163.com, ${ }^{\text {bzjc_1018@163.com, chen575982@163.com, }{ }^{\text {d}} 1677078841 @ q q . c o m}$
}

Keywords: gob; porosity; three-dimensional distribution; CFD.

\begin{abstract}
Grasping the field distribution rule of oxygen, gas and other gases in gob of coalmine is the basis to study the oxidation spontaneous combustion, gas combustion and explosion of gob, having important significance in coal fire prevention and gas control of gob. Due to the destructiveness and concealment of gob, conducting systematic actual measurement for multi-species gas of gob tends to be of greater difficulty, and even harder to achieve. Therefore, the numerical technique has increasingly become the main mean to study the issue. Many scholars at home and abroad had carried out a number of fruitful research work to solve this problem by using the numerical simulation technique: combined with the laboratory test result of rock strength and the relationship of stress - permeability coefficient, P established CFD three-dimensional simulation, conducting the analytical investigation on gas migration rule and gas distribution rule under extraction conditions for gob of longwall face ${ }^{[1]}$; established a CFD three-dimensional model, $\mathrm{R}$ and other scholars particularly studied the distribution rule of gas in gob under different ventilation and extraction conditions ${ }^{[2],[3]}$; by using the developed CFD three-dimensional model, $\mathrm{Hu}, \mathrm{Li}$ and other scholars simulated the flowing ruleof gas in gob ${ }^{[4]}$ and the rhythm rule of gas under the drainage of surface drilling condition ${ }^{[5]}$; developed the CFD model of oxygen distribution in gob, Shi and other scholars studied the distribution rule of oxidation zone in gob and its relation with the amount of air distribution ${ }^{[6,7]}$. Numerical simulation technique based on CFD has been widely applied in researching the gas control, coal fire prevention and other issues of gob.
\end{abstract}

\section{Introduction}

Under consideration of the porosity changes of open-off cut, caving zone and fractured zone, the function describing the porosity of caving zone in the gob has been optimized in this paper by combining the previous research results and the site conditions of gob. Divide the gob into four quadrants, describe the three-dimensional distribution rule of porosity of the overall gob with piecewise function ${ }^{[9]}$, and conduct visualized presentation by taking advantage of Matlab four-dimensional map and programming technology. Compile the optimized porosity distribution function as the corresponding UDF code, load it into the CFD solver module to describe the porosity in the gob $n$, permeability k and other physical properties. Taking Qidong 6135 working surface as an example, the CFD simulation is conducted for the gob, and the optimized model simulation results is more consistent with field data, having better guiding significance in coal fire prevention and gas control.

\section{The establishment of CFD theoretical model for the gob}

\subsection{The optimization of porosity distribution of caving zone and fractured zone in the gob}

Spatial characteristics of flow field in the gob are the main reasons to influence the distribution rule of species gas in the gob, and objective understanding and description of these characteristics are the basis to effectively study the gas distribution rule in the stope. At present, scholars at home and abroad have had more in-depth study on the spatial characteristics of the gob, proposing a variety of function expressions of porosity distribution of the gob. For example, cited the theory of roof strata collapse, Liang and other scholars obtained the two-dimensional distribution rule of porosity on the direction of dip and the direction of face advance in the gob ${ }^{[10]}$; Li and other scholars conducted secondary development against the CFD 3-dimensional model of the gob. 
Combined with the research results of $\mathrm{B}, \mathrm{R}, \mathrm{W}$ and other scholars, considered the changes in the relationship between stress - permeability in the gob, the gob has been divided into four non-uniform quadrants, using a set of tangent hyperbolic equation to describe the three-dimensional permeability distribution and momentum loss source of the gob ${ }^{[9]}$. $\mathrm{Li}$ gives the model expression to describe the caving of roof strata according to "O" rings compaction distribution ${ }^{[13]}$, namely formula (1):

$$
K_{p}(x, y)=K_{p, \min }+\left(K_{p, \operatorname{man}}-K_{p, \min }\right) \times \exp \left(-a_{1} d_{1}\left(1-e^{-\varepsilon 1 a 0 d 0}\right)\right)
$$

Wherein, $K_{p}$ is the broken expansion coefficient of caving in the gob (distribution function), dimensionless; $K_{p, \text { man }}$ is the broken expansion coefficient of initial caving, dimensionless; $K_{p \text {,min }}$ is the broken expansion coefficient after compaction, dimensionless; $a_{0}$ and $a_{1}$ respectively denote the decay rates from the solid wall and working surface, $\mathrm{m}^{-1} ; d_{0}$ and $d_{1}$ respectively denote the distances from the point $(x, y)$ to the working surface and solid wall boundary, $\mathrm{m} ; \varepsilon_{1}$ is the adjustment parameter. The relation of porosity and broken expansion coefficient is formula (2):

$$
\mathrm{n}=1-1 / K_{p}
$$

Integrate formula (1) and (2), take $K_{p \text {,man }}=1.6, K_{p, \text { min }}=1.1, a_{0}=1.6, a_{1}=0.0368$, and $\varepsilon_{1}=0.233$ as examples, the porosity distribution of the front of the gob is shown in Figure 1.

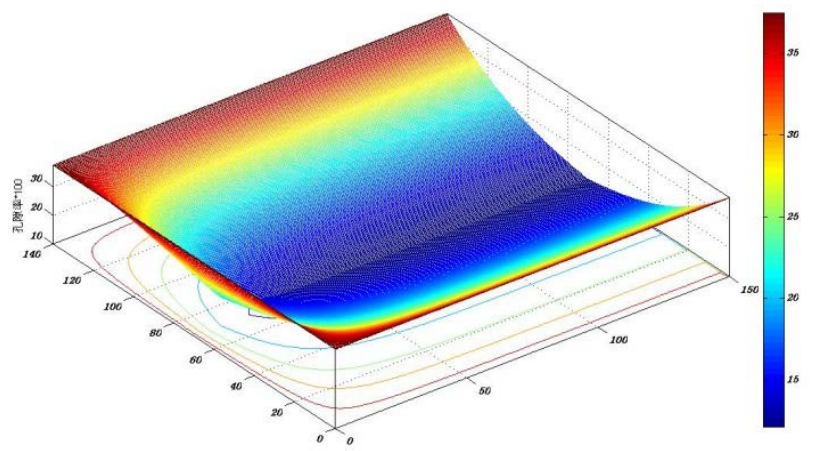

Figure 1 "O" type distribution characteristics of the porosity of the front of the gob

The above function relationship to describe the gob porosity reflects the "O" rings characteristics, but performs deficiently in the characteristics of porosity decrease along with the increase of gob depth. Gob porosity has a corresponding macroscopic variation rule on the three-dimensional spatial direction. It's shown as: along with the depth direction of the gob, from working surface to open-off cut, the porosity increases after decreasing first[11]; in the perpendicular direction of the gob floor, there are two parts, caving zone and fractured zone, and the farther away from the floor, the smaller the porosity; near the open-off cut of the gob and the edge of both sides of the gob, uncompacted "two way" zones exist, and the porosity is relatively small near the region. Based on the research of Li Zongxiang and other scholars, the equation of porosity distribution characteristics of gob is further improved in this paper, as can be seen in formula (3):

$$
\mathrm{n}\left(x_{x} y\right)=1-\left(K_{P_{\text {min }}}+\left(K_{P_{\text {man }}}-K_{P_{\text {min }}}\right) \times \exp \left(-a_{1}\left(d_{1}+b_{1}\right) \times\left(1-e^{-\varepsilon_{1} a_{0}\left(d_{0}+b_{0}\right.}\right)\right)\right)^{-1}
$$

Wherein, $\mathrm{b}_{0}$ is the adjustment parameter along with the depth direction of the gob, $\mathrm{m}$, matching up the decay rate $\mathrm{a} 0$ to fit with the porosity changes at working surface and open-off cut; b1 is the adjustment parameter along with the working face direction, $\mathrm{m}$, matching up the decay rate a1 to fit with the porosity changes at "triangular belt" of both sides of the gob. Combined with the site conditions of the gob, determine a0, b0, a1, b1 and $\varepsilon 1$ values by spreadsheet. The gob have been divided into four non-uniform quadrants. Set the working surface with the length of $140 \mathrm{~m}$, the gob with the depth of $300 \mathrm{~m}, \mathrm{~K}_{\mathrm{p}}, \mathrm{man}=1.6, \mathrm{Kp}, \mathrm{min}=1.1$, $\mathrm{a} 0=0.268$, b0,former=0, b0,latter=8,a1=0.0368, $\mathrm{b} 1=10$, and $\varepsilon 1=0.233$,the two-dimensional distribution of the porosity of gob caving zone in the section parallel the floor can be seen in Figure 2. In Figure 2, it can be reflected: the porosity at open-off cut is larger than that at compaction zone in central gob, and the maximum is about 0.3; near the edge of both sides of the gob, smaller scale of uncompacted "two way" zones exist, and the maximum value of porosity is about 0.27 ; near the working surface, the maximum value of porosity is about 0.375 ; the closer to the compaction zone, the smaller the porosity value is. 


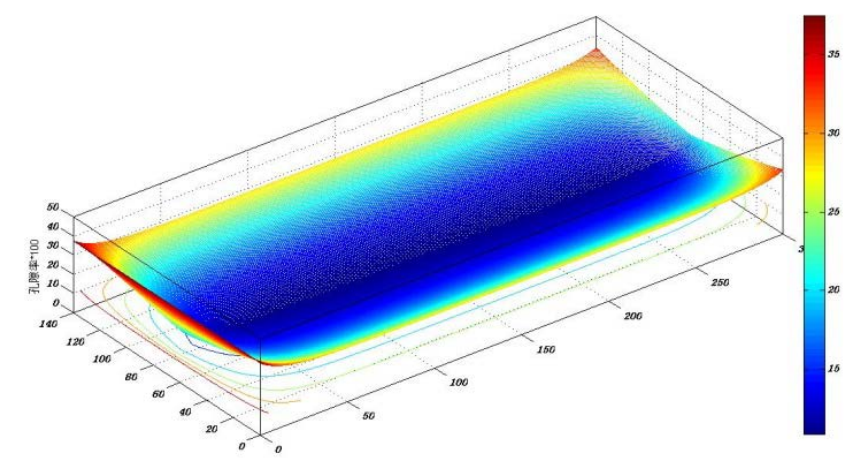

Figure 2 Distribution of the porosity of gob caving zone (in the section parallel the floor)

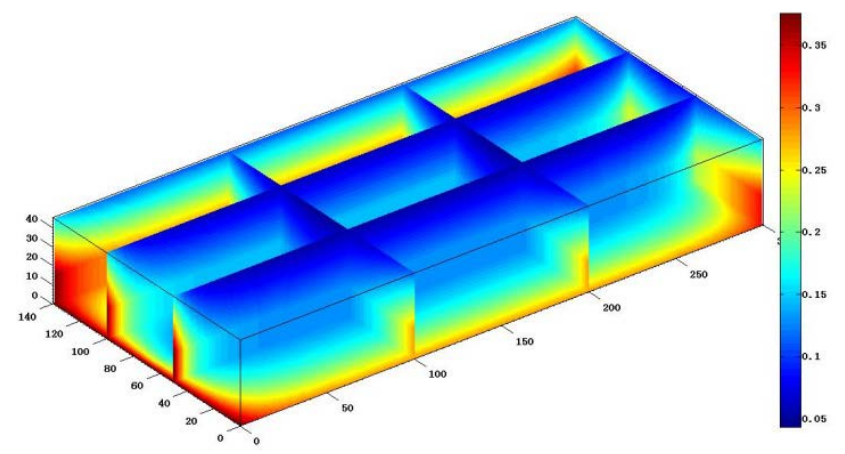

Figure 3 Four-dimensional display diagram of porosity in the gob

During the three-dimensional model of porosity, not only the porosity changes along with the direction of section parallel to the floor, but also the changes of caving zone and fractured zone on the vertical direction shall be taken into account ${ }^{[12][13]}$. In this three-dimensional model, the caving zone is taken as 5 times of mining height, and the fractured zone is taken as 10 times of mining height. Due to the small height of the caving zone, it can be considered that the porosity within the caving zone changes little along the height. The porosity within fractured zone has significantly reduced on the basis of caving zone porosity, gradually reducing to 0.1 and even below with the increase of height ${ }^{[14]}$. Based on the above variation rule, by using the four-dimensional figure technology of Matlab ${ }^{[15]}$, the author of this paper compiled the optimized porosity distribution function into the files of Script. $m$ and Function.m, to generate the four-dimensional figure display program of porosity distribution of caving zone and fractured zone in the gob. Enter the corresponding working surface length, gob length, mining height, caving zone height, fractured zone height and other variables into the program, the distribution image of porosity of the caving zone and fractured zone under this gob condition can be displayed. Corresponding to the gob model in Figure 2, taking the mining height of $3 \mathrm{~m}$ as an example, Figure 3 shows the corresponding four-dimensional figure of porosity distribution in the gob. In the Figure, $\mathrm{x}$-axis, $\mathrm{y}$-axis and z-axis three-dimensional coordinates respectively denote the gob length, working surface length and the height away from the gob floor, and Matlab indicates the value of the fourth dimension by color, that is, the porosity values of the position.

\subsection{Flow model in porous media of the gob}

The CFD foundation is based on Navier-Stokes equations, which are a set of partial differential equations to describe the fluid conservation law, including the mass conservation equation, energy conservation equation and momentum conservation equation ${ }^{[16]}$. In the CFD simulations, the gob is a porous media zone, so that the gas migration in the gob is in line with the mass, energy and momentum conservation equations. The momentum equation in porous media can be seen in formula (4):

$$
\frac{\theta}{A t}\left(\rho \mu_{i}\right)+\frac{\theta}{A x z}\left(\rho \mu_{i} \mu_{j}\right)=-\frac{\theta p}{A x_{i}}+\frac{\theta t_{i j}}{A x_{z}}+\rho g_{\mathrm{i}}+S_{i} \quad(\mathrm{i}=\mathrm{x}, \mathrm{y}, \mathrm{z})
$$

Wherein, $\mathrm{Si}$ is the momentum sink in the porous media, consisting of the viscous loss term and inertial loss term two parts ${ }^{[17]}$, as can be seen in formula (5):

$$
S_{i}=\frac{1}{k} \mu v_{i}+0.5 C_{2} \rho v_{i}\left|v_{i}\right| \quad(i=x, y, z)
$$

In the formula (5), $\mathrm{k}$ is the permeability of the gob, $\mathrm{C} 2$ is the inertial resistance factor. Based on the Carman-Kozeny formula, the relation of the gob porosity $n$ and the gob permeability $\mathrm{k}$ can be given in formula (6):

$$
\mathrm{k}=\frac{\mathrm{k}_{0}}{\mathrm{n} \cdot 2 \mathrm{~s} 1 \mathrm{x}} \times\left[\frac{\mathrm{n}^{3}}{(1,-\mathrm{n})^{2}}\right]
$$

In formula (6), the magnitude of $\mathrm{k} 0$ is $10-9 \mathrm{~m} 2$ [19]. Enter the porosity equation (3) into the Carman-Kozeny equation, the equations of gob permeability distribution can be gotten. Write the distribution equations of the gob permeability $\mathrm{k}$ as UDF to load and solve, and the CFD model can 
be made more close to the real gob. The model consists of two parts, the roadway and the gob , using turbulence model to solve. Due to the small flow field velocity in the porous medium model of the gob, which can be viewed as a laminar flow field, the gob can be set as Laminar Zone.

\subsection{Transmission model of multi-species in the gob}

A variety of complex physical changes and chemical reactions exist in the gob, including the oxidation of coal and gas emission in the gob and the artificially injection of nitrogen and other fire preventing and extinguishing materials. These factors have a very important impact on the distribution of oxygen, gas, nitrogen and other gas. In the CFD simulations, according to the species' law of conservation of mass, the species mass-conservation equation of the species $S$ can be gotten ${ }^{[17]}$, which can be seen in formula (7):

$$
\frac{\partial\left(\rho c_{s}\right)}{A t}+\operatorname{div}\left(\operatorname{puc}_{s}\right)=\operatorname{div}\left(D_{s} \operatorname{grad}\left(\rho c_{s}\right)\right)+S_{s}
$$

In the formula (7), cs is the volume concentration of the species $\mathrm{S}, \rho c_{s}$ is the mass concentration of the species, Ds is the diffusion coefficient of the species, and Ss is the mass generation rate of the species in the system per unit time per unit volume. The four items in the above formula respectively denote the time rate of change, the convective term, diffusion term and reaction term of the species. With the field measurement, sampling experiments and other methods, compile the obtained oxygen consumption, gas emission quantity, nitrogen injection volume and other items in the gob as the corresponding UDF formula to load, that is, the corresponding SO2, SCH4, SN2 and other items, so that the change rule of the gas field in the gob can be closer to the real gob, making the CFD simulation closer to the actual situation.

\section{Three-dimensional modeling of 6135 gob}

(1) The incline length of working surface is $200 \mathrm{~m}$, and the angle of inclination is $14^{\circ}$, the airway side is higher than the roadway side, the incline length of the gob is taken as $600 \mathrm{~m}$, the caving zone of the gob is $15 \mathrm{~m}$, the fractured zone is $30 \mathrm{~m}$. Set the component of the gravity of this model along with the working surface direction as $2.3708 \mathrm{~m} / \mathrm{s} 2$, and the component along with the direction perpendicular the gob floor is $9.5089 \mathrm{~m} / \mathrm{s} 2$.

(2) Regard the gob as the porous media flow field.

(3) In the gob, the main gas is N2, O2 and CH4.

Meshing: use Gambit software to establish the calculation model and conduct meshing, and the model meshing is shown in Figure 4.

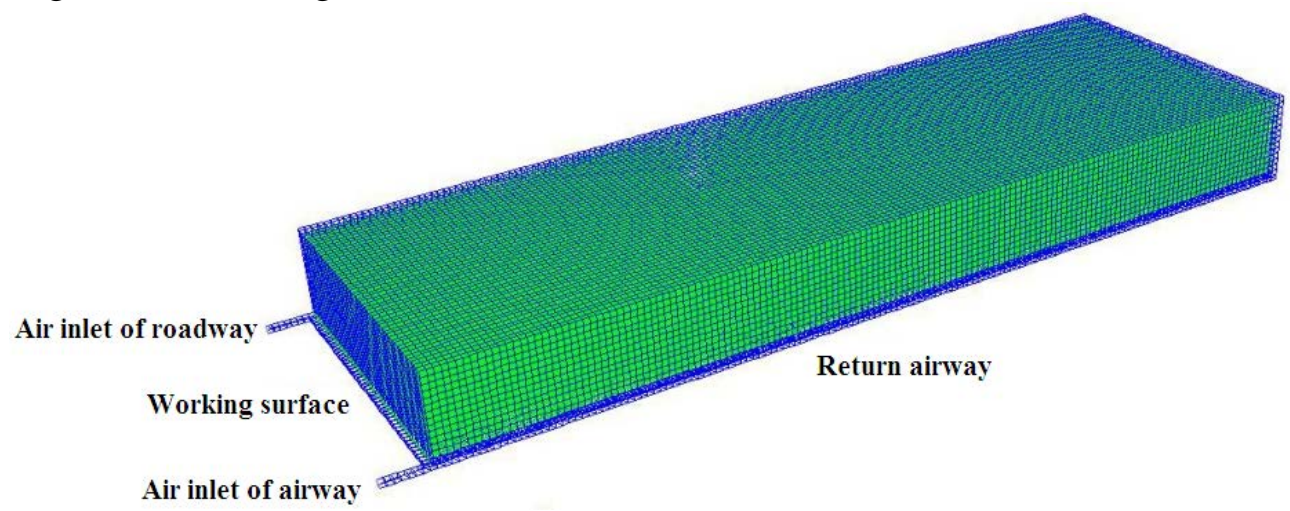

Figure 4 Meshing diagram of gob model

\section{Simulation results analysis of gas distribution in the gob of Qidong 6135 working surface}

The ventilation of 6135 working surface is Y type, and the airway Q1 = 350m3/min, roadway Q2 $=500 \mathrm{~m} 3 / \mathrm{min}$. The main gas source is the release of coal that containing gas in the gob, and the oxygen consumption is mainly due to the float coal oxidation. In accordance with the actual situation and the measured data, the terms of gas floor emission source and gob oxygen consumption source have been set in this model ${ }^{[19]}$. 


\subsection{Oxygen field distribution of 6135 gob}

The three-dimensional distribution of oxygen in 6135 gob is shown in Figure 5. In order to verify the reliability of the simulation, with the method of laying beam tube for the gob in the field, conduct actual measurement for the oxygen concentration on the roadway side of the gob. Figure 6 shows the comparison of stimulated data and measured data at corresponding position. As can be seen from Figure 6, the oxygen concentration datum obtained both from simulated data and measured data showed a fluctuating decline trend with increasing distance from the working surface, and in overall, the numerical simulation results and field measurement data have a good goodness of fit. Figure 7 is the distribution of oxygen concentration at the sections of different height from the floor.

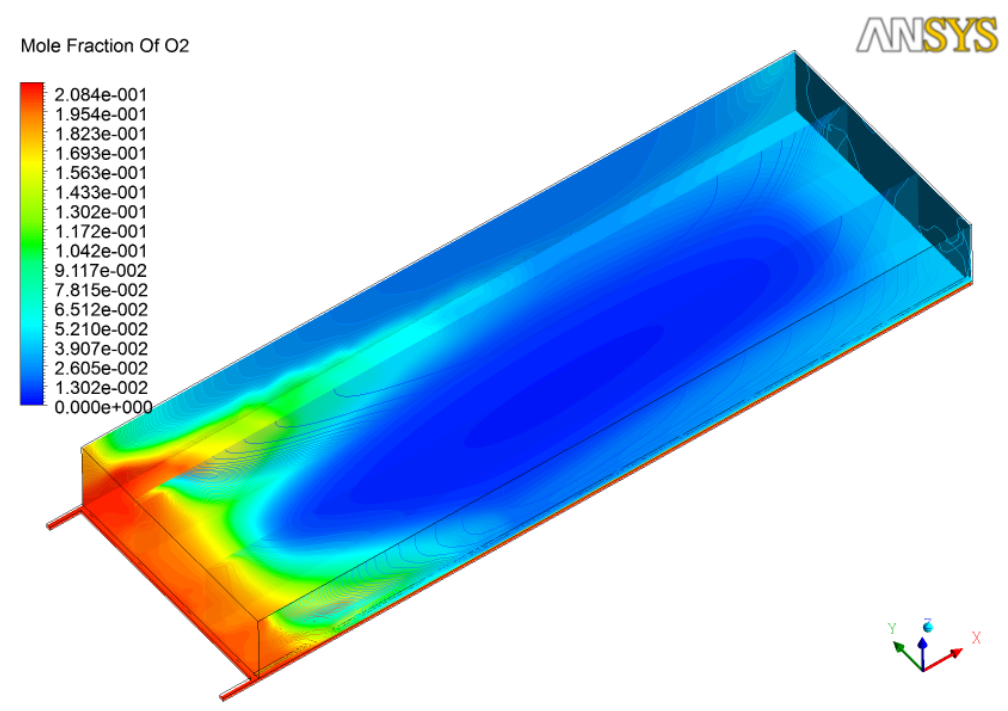

Figure 5 The three-dimensional distribution of oxygen in the gob

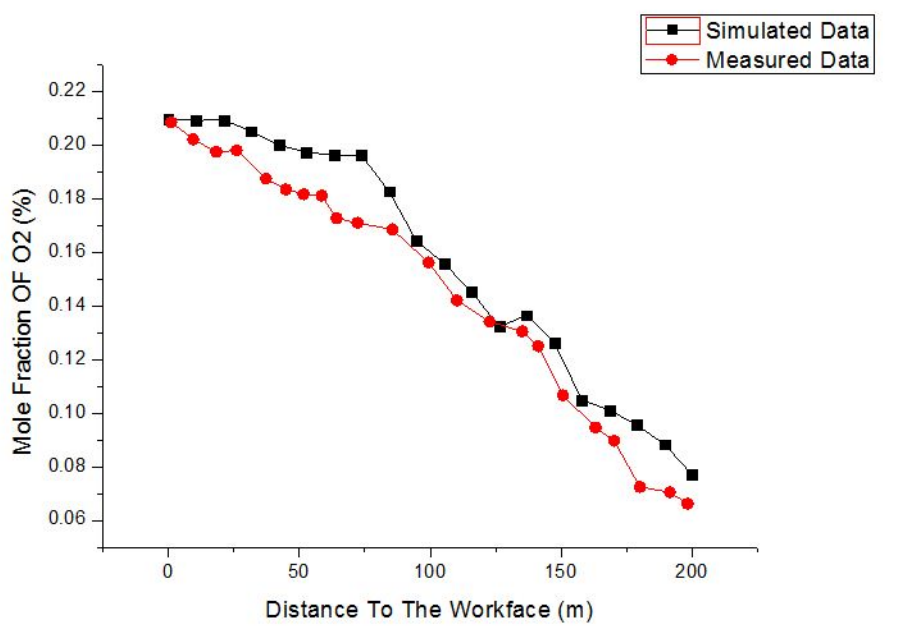

Figure 6 Oxygen data comparison on the roadway side of the gob

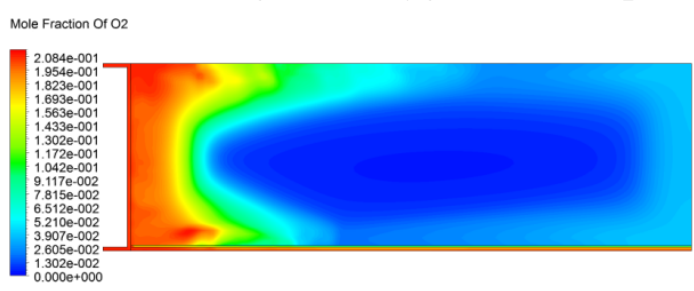

(a) $\mathrm{Z}=1 \mathrm{~m}$

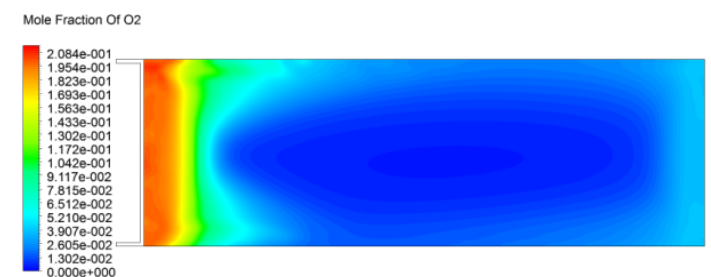

(b) $\mathrm{Z}=10 \mathrm{~m}$ 


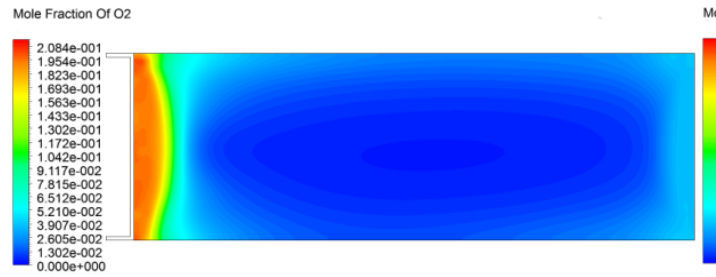

(c) $\mathrm{Z}=30 \mathrm{~m}$

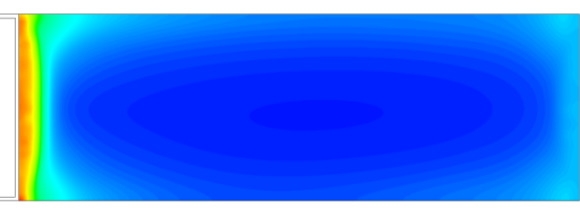

(d) $\mathrm{Z}=40 \mathrm{~m}$

Figure 7 Distribution of oxygen concentration in the gob (in the section parallel the floor)

Through the simulation results, it can be seen:

(1) The oxygen concentration decreases gradually along the depth of the gob, and is slightly higher on the roadway side than the airway side at the same depth. There are two reasons. First, the average angle of inclination of 6135 working surface is $14^{\circ}$, and the roadway is located in a lower side, what's more, air leakage will gather more in the low side, so that the gas with lighter density diverts to the airway on the upper side, causing the lower percentage of oxygen volume and higher percentage of gas volume on airway side. Second, compared with airway, the roadway has a larger amount of wind and air leakage, so that there is the higher oxygen concentration at the same depth. Oxygen volume concentration in the range of $8 \%$ to $18 \%$ can be seen in the figure. The oxidation zone on roadway side is deeper than the airway side.

(2) On the inner edge of the gob, the oxygen volume concentration decreases with the increase of height. With the height increases, the porosity drastically reduces [21], the viscous resistance increases sharply, the air leakage entering into the high area is less, so that the dilution effect of precipitation gas on oxygen is obvious at this place.

(3) The possible oxidation thermal storage zone at each height of the 6135 gob (namely, the oxygen volume concentration in the range of $8 \%$ to 18\%) can be seen in Figure 7 . It can be seen, with the increase of height, the thermal storage zone moves to the working surface direction. Within the height of $0 \sim 10 \mathrm{~m}$ from the floor, the oxidation zone is in the range of about $50 \mathrm{~m} \sim 220 \mathrm{~m}$ close to the roadway direction, and the thermal storage zone is in the range of about $40 \mathrm{~m} \sim 100 \mathrm{~m}$ on the direction of central working surface and in the range of about $50 \mathrm{~m} \sim 170 \mathrm{~m}$ close to the airway direction. In overall, the oxidation thermal storage zone distributes in U-shaped ${ }^{[20]}$.

\subsection{CH4 field distribution of $6135 \mathrm{gob}$}

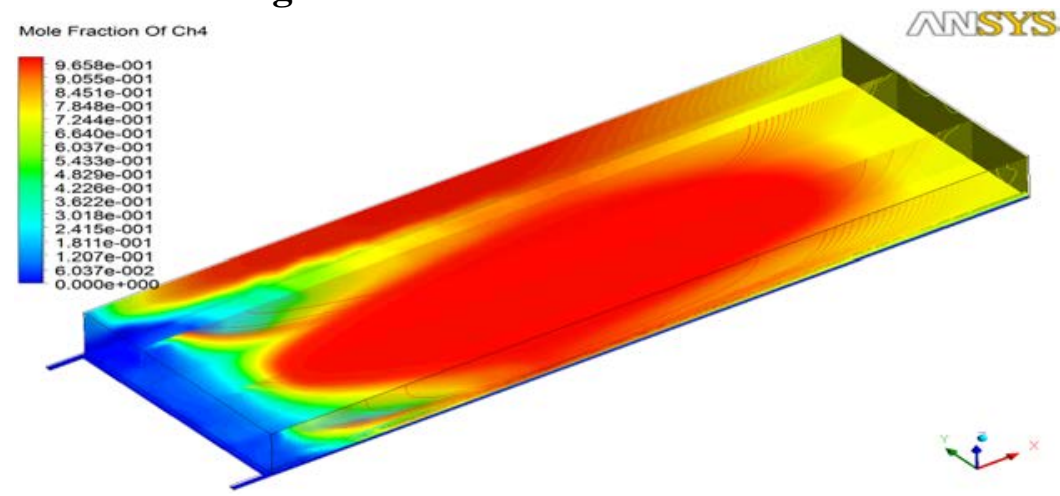

Figure 8 The three-dimensional distribution of $\mathrm{CH}_{4}$ in the gob

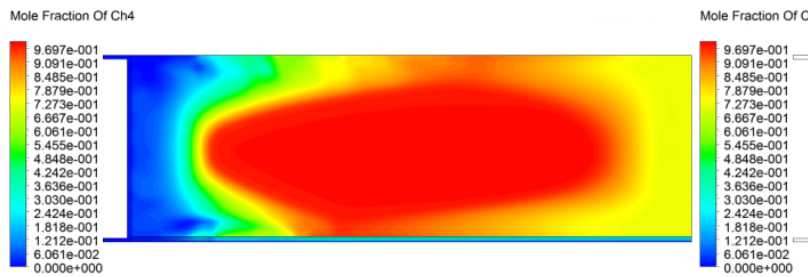

(a) $\mathrm{Z}=1 \mathrm{~m}$

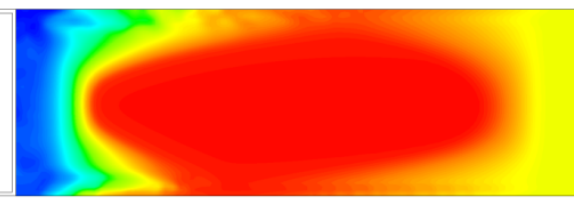

(b) $\mathrm{Z}=10 \mathrm{~m}$ 


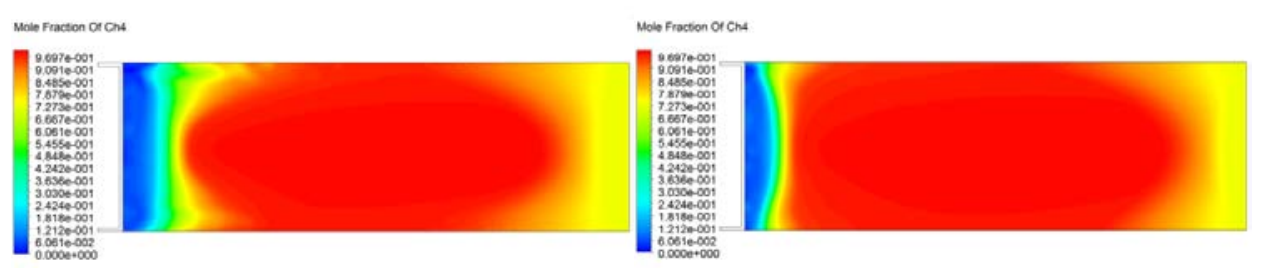

(c) $\mathrm{Z}=30 \mathrm{~m}$

(d) $\mathrm{Z}=40 \mathrm{~m}$

Figure 9 Distribution of $\mathrm{CH}_{4}$ concentration in the gob (in the section parallel the floor)

Through the simulation results of Figure 8 and 9, it can be seen:

(1) Along with the strike, the volume concentration of gas near the gob interior gradually increases. Along with the inclination, the concentration of gas near the return airway side increases faster than the side of roadway air inlet. Similar to the above corresponding distribution rule of oxygen, it is the result subject to dual factors of gravity and air volume.

(2) It can be reflected in this simulation that the $\mathrm{Y}$ type ventilation has avoided the gob gas flocking to the upper corner of working surface, solving the gas problem on the upper corner.

(3) It can be noted that volume percentage of gas near the open-off cut at the rear of the gob slightly decreases compared with the central region of the gob. With the longest emission time at open-off cut, the gas emission has been less. Air leakage flow slowly goes deep into the open-off cut along with the "two way" zones with larger porosity on the roadway side of the gob, and gradually dilutes the gas emiting from this place and takes the gas away with the air leakage field. Therefore, the gas concentration here decreases slightly.

(4) The gas volume concentration is larger in the compaction area of the intermediate gob. In this area, the porosity is small and the amount of gas emission is relatively larger, so that the desorbed gas can quickly fill the void in the region, and both the speed and volume of the air leakage flow are the lowest when through this region since the lowest porosity here, resulting in the accumulation condition of gas here.

\section{Conclusion and discussion}

(1) The work amount is big and the diffculty is high to actually measure the distribution rule of oxygen and gas in the gob, and the pipe laying, gas samples taking and other processes are susceptible to external interference to lead to deviation. Using CFD simulations can obtain the relatively consistent distribution of gas field with the field, which has better guiding significance in coal spontaneous combustion and gas control of the gob.

(2) Combined with the porosity variation at working surface, open-off cut, "two way" zones and other places, as well as inside the caving zone and fractured zone, two adjustment parameters are added in this paper, so that the equation has a flexible maneuverability and can combine different field measurement data to fit, so as to be even closer to the real situation.

(3) The CFD simulation results based on Qidong 6135 working surface have delineated the three-dimensional distribution of oxidation thermal storage zone. Taking the appropriate nitrogen injection, three-phase foam injection and other fire preventing and extinguishing measures against the float coal within the range, the effect is more effective. The simulation results of gas distribution based on 6135 gob can be used to guide the optimal design of high drilling.

\section{References}

[1] T. Ren, R. Balusu. Modelling of goaf gas migration for control of spontaneous combustion. The AusIMM Bulletin, Journal of the Australasian Institute of Mining and Metallurgy. 6(2005):55 58.

[2] R. Balusu, T. Ren, P. O’Grady, N. Winkelmann, K. Schiefelbein and M. Loney. Proactive inertisation to prevent heatings in active longwall panels. 31st International Conference of Safety in Mines Research Institutes. Brisbane, Australia, 2005.

[3] M. Wendt, R. Balusu. CFD modeling of long wall goaf gas flow dynamics. Coal and Safety 20(2002): 17 34. 
[4] HU Qian-ting,LIANG-Yun-pei,LIU Jian-zhong. CFD simulation of goaf gas flow patterns[J]. Journal of China Coal Society. 2007, 32(7):719 723.

[5] LI Zong-xiang. Study on numerrical simulation of gas cission regularity and boundary condition of the goaf in coal caving of the fully-mechanized[J]. Journal of China Coal Society. 2002, 27(2): 173 178.

[6] SHI Guoqing,WANG Deming,XI Zhilin,etc. Numercial Simulation of Oxygen Concentration Distribution in Gob Areas Based on FLUENT[J]. Coal Science and Technology. 2009, 37(6):76 79.

[7] CAO Kai,SHI Guo-qing,Wang De-ming. Dangerous Region Judgment of Spontaneous Combustion in Goaf of Fully Mechanized Top Coal Caving Mining Face with Shallow Depth Seam[J]. Coal Science and Technology. 2012, 40(1):57 59.

[8] Guo-qing,Wang De-ming,ZHONG Xiao-xing. Mathematical simulation study on characteristics of three-phase foam seepage in goaf[J]. Journal of China Coal Society. 2011, 36(8):1329 1333.

[9] LI Guo-jun. Tiefa Mining in high gas and low permeability coal seams gas industry research and engineering practice [D]. XuZhou: China Mining University, 2007.

[10] LIANG Yun-tao,ZHANG Teng-fei,WANG Shu-gang. Heterogeneous model of porosity in gobs and its airflow field distribution[J]. Journal of China Coal Society. 2009, 34(9):1203 1207.

[11] Li Shu-gang,Qian Ming-gao,Shi Ping-wu. Study on Bed-separated Fissures of Overlying Stratum and Interstice Perm Eability in Fully-mechanized Top Coal Caving[J]. Chinese Journal of Rock Mechanics and Engineering. 2000, 19(5):604 607.

[12] Li Lian-chong,Tang Chun-an,Liang Zheng-zhao. Investigation on overburden strata collapse around coal face considering effect of broken expansion of rock[J]. Rock and Soil Mechanics. 2010, 31(11): 3537 3541.

[13] Li Zong-xiang,Yi Gang,Wu Jian-guo. Study on spontaneous combustion distribution of goal based on the "O" type risked falling and non-uniform oxygen[J]. Journal of China Coal Society. 2012, 37(3):484 489.

[14] ZHANG Chun,TI Zheng-yi,LI Zong-xiang. Porosity of Goaf in Three Dimensions[J]. Journal of Yangtze River Scientific Research Institute. 2012, 29(6):52 57.

[15] Liu Bao-zhu,Su Yan-hua,Zhang Hong-lin. Matlab7.0 from entry to the master[M]. Beijing:People's Posts and Telecommunications Press, 2010.

[16] Lin Jian-zhong,Ruan Xiao-dong,Chen Bang-guo. Fluid Mechanics [M]. Beijing: Qinghua university press, 2005.

[17] Wang Fu-jun. Computational fluid dynamics analysis -- the principle and application of CFD software [M]. Beijing: Qinghua university press, 2004.

[18] Zhu Hong-jun,Lin Yuan-hua,Xie Long-han. Fluid analysis and Simulation of FLUENT 12[M]. Beijing: Qinghua university press,2011.

[19] LI Zong-xiang,Hai Guo-zhi,QIN Shu-yu. Numerical simulation and visual display of air flow pattern in goaf[J]. Journal of China Coal Society. 2001, 26(1):76 80.

[20] Yu Ming-gao,Zhao Zhi-jun, Chu Ting-xiang,etc. The influence of gas drainage on goaf spontaneous combustion and its prevention measures[J]. Journal of Henan Polytechnic University (Natural Science). 2011, 30(5):505 509.

[21] Gao Jian-liang,Wang Hai-sheng. Influence of Permeability Distribution on Airflow Field of Leakage in Gob[J]. China Safety Science Journal. 2010, 20(3):81 85. 